\title{
Thiol-Disulfide balance in patients with renal colic
}

Yavuz OTAL ${ }^{1}$, Serkan DEMiRCAN ${ }^{2}$, Alp ŞENER ${ }^{1}$, Murat ALIŞIK ${ }^{4}$, Fadime Güllü ERCAN HAYDAR ${ }^{1}$, Özcan EREL ${ }^{4}$, Ayhan ÖZHASENEKLER ${ }^{3}$, Servan GÖKHAN ${ }^{3}$

\footnotetext{
${ }^{1}$ Department of Emergency Medicine, Ataturk Education and Research Hospital, Ankara, Turkey.

${ }^{2}$ Department of Emergency Medicine, Kecioren Education and Research Hospital, Ankara, Turkey.

${ }^{3}$ Department of Emergency Medicine, Medical Faculty, Yıldırım Beyazit University, Ankara, Turkey.

${ }^{4}$ Department of Biochemistry, Medical Faculty, Yıldırım Beyazıt University, Ankara, Turkey.
}

\section{SUMMARY}

This study aimed to investigate thiol-disulfide balance in patients with renal colic who were frequently referred to emergency services and also to discuss its potential clinical use.

Blood samples were obtained from 32 patients diagnosed with renal colic before treatment in the emergency department. Then, the serum thiol-disulfide levels were measured using a novel method. The patients also underwent a complete blood count test and renal ultrasonography. The thiol-disulfide values were compared statistically between the patient (those with renal colic) and control groups (healthy volunteers).

The mean native thiol level was significantly less in the patient group than in the control group. In addition, the disulfidel native thiol and disulfide/total thiol ratios were significantly higher in the patient group than in the control group ( $P<$ 0.05).

This study found a significant difference in the thiol-disulfide balance of patients with renal colic compared with healthy volunteers. The mean native thiol and total thiol levels decreased in the patient group. It is believed that these markers may be indicative of inflammation in patients with renal colic.

Key words: Oxidative stress, renal colic, thiol-disulfide balance, urolithiasis

\section{INTRODUCTION}

Renal colic is a common clinical condition affecting $11 \%$ of the population in Turkey (1). Genetic, metabolic, and anatomic factors, besides dietary habits, are involved in the etiology of renal colic. People excrete crystals through the kidney every day. Calcium oxalate and phosphate crystals have an important role in stone formation. These stones constitute a risk for urinary tract obstruction and kidney damage. Cells under stress in the urinary system produce oxygen free radicals. This poses a greater risk of developing kidney damage. As a result, the development of oxidative stress leads to inflammation and damage to the urinary system.

Oxidant and antioxidant parameters have been frequently examined in recent studies $(2,3)$. However, the measurement methods used in these studies are both complex and expensive. The thiol-disulfide balance used in this study could measure oxidative stress both inexpensively and simply by a novel method (4). It is believed that these markers may be indicative of inflammation in patients with renal colic.

\section{MATERIALS AND METHODS}

A total of 32 patients diagnosed with renal colic in the emergency department were included in the study. Patients with additional diseases that could cause oxidative stress were excluded from the study. Blood and urine samples were 
TABLE 1: Age distribution and blood values of patients and healthy volunteers included in the study.

\begin{tabular}{|c|c|c|c|}
\hline Parameters & $\begin{array}{l}\text { Control } \\
n=36\end{array}$ & $\begin{array}{l}\text { Renal colic } \\
n=32\end{array}$ & $P$ value \\
\hline Age (year) & $40.0 \pm 10.4$ & $40.3 \pm 10.5$ & 0.904 \\
\hline Native thiol ( $\mu \mathrm{mol} / \mathrm{L})$ & $445.3(69.2)$ & $403.5(75.7)$ & $<0.001$ \\
\hline Total thiol ( $\mu \mathrm{mol} / \mathrm{L})$ & $493.8 \pm 54.5$ & $451.1 \pm 54.1$ & 0.002 \\
\hline Disulfide ( $\mu \mathrm{mol} / \mathrm{L})$ & $16.6 \pm 4.8$ & $25.4 \pm 9.1$ & $<0.001$ \\
\hline Disulphide/Native thiol ratio (\%) & $3.6 \pm 1.1$ & $6.6 \pm 3.1$ & $<0.001$ \\
\hline Disulphide/Total thiol ratio (\%) & $3.4 \pm 1.0$ & $5.7 \pm 2.2$ & $<0.001$ \\
\hline Native thiol/Total thiol ratio (\%) & $93.2 \pm 1.9$ & $88.6 \pm 4.5$ & $<0.001$ \\
\hline \multicolumn{4}{|c|}{$\begin{array}{l}\text { Normally distributed data (parametric data) were expressed as mean } \pm \text { standard deviation, whereas non-normally distributed data (nonparametric } \\
\text { data) were expressed as median (IQR). } P \text { values for parametric data were calculated using the Student } t \text { test, whereas } P \text { values for nonparametric data } \\
\text { were calculated using the Mann-Whitney } U \text { test. A } P \text { value }<0.05 \text { was considered statistically significant. } \\
\text { The patient group included } 15 \text { women and } 21 \text { men, whereas the patient group included } 9 \text { women and } 23 \text { men. No statistically significant difference } \\
\text { was found between the two groups in terms of gender distribution (in the Pearson Ki-Kare test } P=0.243 \text { ). }\end{array}$} \\
\hline
\end{tabular}

obtained from these patients before starting treatment. The thioldisulfide levels were measured using the Erel method without incubating blood samples (4). All patients also underwent renal ultrasonography in the radiology unit. Analgesics and intravenous isotonic fluid infusions were used to treat all patients.

The IBM SPSS Statistics version 15.0 was used for statistical analysis. The Kolmogorov-Smirnov test was used to check whether a variable was normally distributed. After the one-way analysis of variance was used to compare normally distributed variables, the Fisher's least significant difference test was used to compare groups. After the Kruskal-Wallis test was used to compare nonnormally distributed variables, the Mann-Whitney U test was used to compare groups. The relationships between numerical variables were analyzed using the Pearson's and Spearman's correlation tests. A Pvalue $<0.05$ was considered statistically significant.

The study protocol was approved by the local ethics committee. Written informed consent was obtained from each patient.

\section{RESULTS}

The age distribution and blood values of 32 patients and 36 healthy volunteers included in the study are shown in Table 1.
No statistically significant difference in the mean age was found between the two groups.

As shown in Figure 1, the mean native thiol level was 403.5 (75.7) in the patient group and $445.3(69.2)$ in the control group $(P<$ 0.001). The mean total thiol level was $451.1 \pm 54.1$ in the patient group and 493.8 \pm 54.5 in the control group ( $P=0.002$ ) (Fig. 2). The disulfide-native thiol and disulfide-total thiol ratios were significantly higher in the patient group than in the control group $(P<0.001)$.

\section{DISCUSSION}

Dynamic thiol-disulfide homeostasis plays a critical role in organisms. Changes in the thiol-disulfide balance serve as components for antioxidant protection, detoxification, regulation of enzymatic activity, and cellular signaling mechanisms $(5,6)$. Changes in thiol-disulfide homeostasis have been associated with various diseases, such as DM, cancer, migraine, hyperemesis gravidarum, and chronic renal failure (7-12). Cysteine and its derivatives are major thiol-disulfide compounds in the plasma. As a result, cysteine is important in both structural functions and redox systems (such as thiol-disulfide changes) (13). Disulfides such as cysteine are members of thiol-based redox regulation (14). 


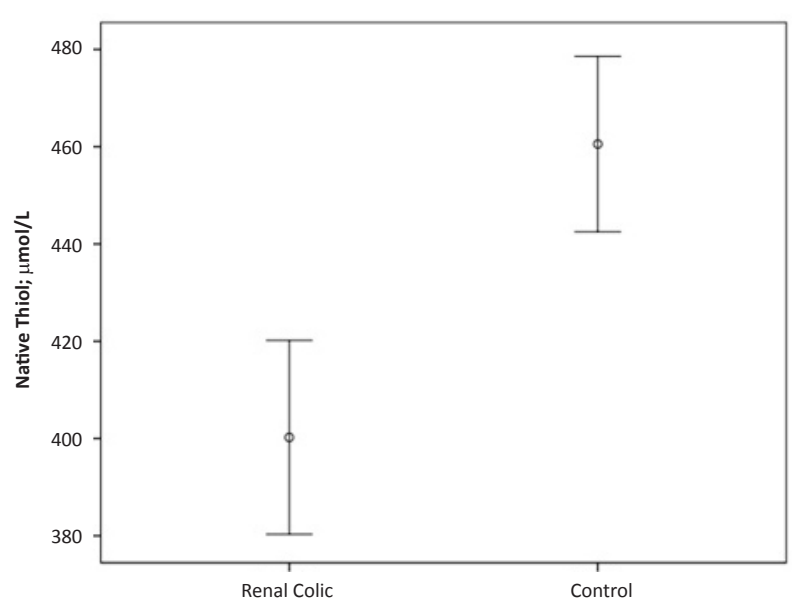

FIGURE 1: The ratio of native thiol between patient and control group.

Although the thiol-disulfide balance could be measured unilaterally until now, it can be measured bilaterally by a novel method developed by Erel et al. (4). This novel study explored the relationship between disease and thiol levels using the aforementioned method in patients diagnosed with renal colic. The total thiol, native thiol, and disulfide levels were measured. It was found that the mean native thiol and total thiol levels were significantly less in the patient group than in the control group.

Oxidative stress has an important role in many diseases (4,15-18). Some studies have shown an increase in oxidative stress in urinary stone diseases in children (19). The fact that oxygen free radicals resulting from renal tubular damage induced by calcium oxalate and calcium phosphate stones increase oxidative stress has been investigated both in tissue cultures and in animal experiments (20). These calcium stones that cause renal colic lead to oxidative stress and cellular damage in the urinary system. Oxygen free radical inhibitors or antioxidants (such as vitamin E, glutathione, and $\mathrm{N}$-acetylcysteine) are extensively used to prevent this situation (21-23). However, a previous study showed that oxidative stress did not significantly increase in patients with renal colic (24). This study found that the thiol-disulfide balance shifted in favor of thiol due to significant elevations in the thiol level. Although many oxidative stress markers have been explored in patients with urolithiasis, the thiol-disulfide balance has not been studied. This

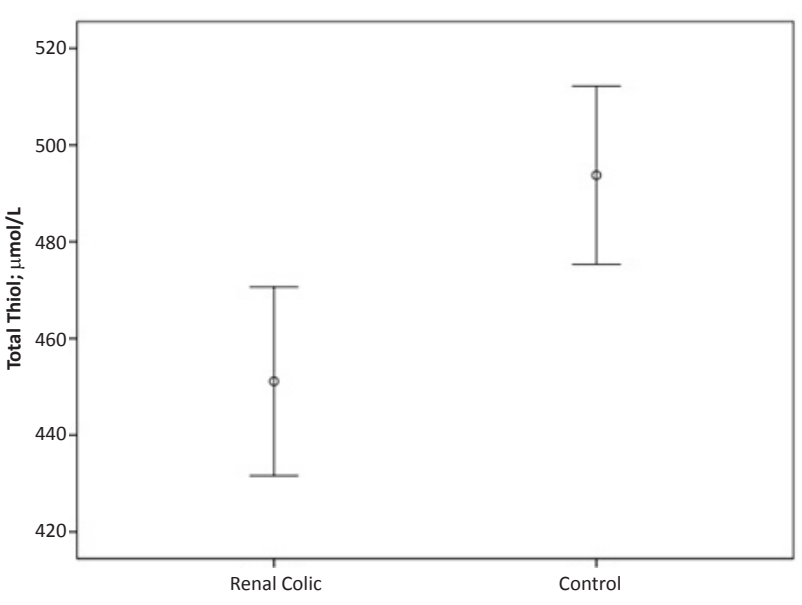

FIGURE 2: The ratio of total thiol between patient and control group.

was a novel study conducted using the Erel method, a new method in patients with renal colic. Total oxidant level was previously used as an indicator. In addition, high levels of total thiol can be regarded as an indicator of oxidative stress.

This study indicated that antioxidant treatments could be used to prevent renal damage in renal colic. A limitation of the study was that the findings could not be applied in additional diseases such as diabetes mellitus, and hypertension.

\section{REFERENCES}

1. Muslumanoglu AY, Binbay M, Yuruk E, Akman T, Tepeler A, Esen T, Tefekli AH. Updated epidemiologic study of urolithiasis in Turkey.I: changing characteristics of urolithiasis. Urol Res 2011;39:309-314.

2. Khan SR. Is oxidative stress, a link between nephrolithiasis and obesity, hypertension, diabetes, chronic kidney disease, metabolic syndrome? Urol Res 2012;40:95-112.

3. Carrasco-Valiente J, Anglada-Curado FJ, Aguilar-Melero $P$, Gonzalez Ojeda R, Muntane-Relat J, Padillo-Ruiz FJ, RequenaTapia MJ. State of acute phase markers and oxidatine stress in patients with kidney stones in the urinary tract. Actas Urol Esp 2012;36:296-301.

4. Erel O, Neselioglu S. A novel and automated assay for thiol/ disulphide homeostasis. Clin Biochem. 2014; 47: 326-32.

5. Biswas S, C hida A S, R ahman I. R edox modifi cations of protein thiols: emerging roles in cell signaling. Biochem Pharmacol. 2006; 71: 551-64.

6. Circu M L, Aw TY. Reactive oxygen species, cellular redox systems, and apoptosis. Free Radic Biol Med. 2010; 48:749-62.

7. Matteucci $E$, Giampietro $O$. Thiol signalling network with an eye to diabetes. Molecules 2010; 15(12): 8890-8903. 
8. Prabhu A, Sarcar B, Kahali S, Yuan Z, Johnson JJ, Adam KP et al. Cysteine catabolism:a novel metabolic pathway contributing to glioblastoma growth. Cancer Res 2014; 4(3): 787-796.

9. Rodrigues SD, Batista GB, Ingberman M, Pecoits-Filho R, Nakao LS. Plasma cysteine/cystine reduction potential correlates with plasma creatinine levels in chronic kidney disease. Blood Purif 2012; 34(3-4): 231-237.

10. Kundi H, Ates I, Kiziltunc E, Cetin M, Cicekcioglu H, Neselioglu S, Erel O, Ornek E.A novel oxidative stress marker in acute myocardial infarction; thiol/disulphide homeostasis. Am J Emerg Med 2015;33(11):1567-71.

11. Eren Y, Dirik E, Neşelioğlu S, Erel Ö. Oxidative stress and decreased thiol level in patients with migraine: cross-sectional study. Acta Neurol Belg 2015;115(4):643-9.

12. Ergin M, Cendek BD, Neselioglu S, Avsar AF, Erel O. Dynamic thioldisulfide homeostasis in hyperemesis gravidarum. J Perinatol. 2015;35(10):788-92.

13. Hansen RE, Østergaard $H$, Winther JR. Increasing the reactivity of an artificial dithioldisulfide pair through modification of the electrostatic milieu. Biochemistry 2005; 44:5899-5906

14. Wouters MA, George RA, Haworth NL. 'Forbidden' disulfides: their role as redox switches. Curr Protein Pept Sci 2007; 8:484-495.

15. Ates I, Kaplan M, Inan B, Alısık M, Erel O, Yilmaz N, Guler S. How does thiol/disulfide homeostasis change in prediabetic patients? Diabetes Res Clin Pract 2015 S0168-8227.

16. Maes $M$, Galecki $P$, Chang YS, Berk $M$. A review on the oxidative and nitrosative stress (O\&NS) pathways in major depression and their possible contribution to the (neuro) degenerative processes in that illness. Prog Neuropsychopharmacol Biol Psychiatry 2011;35:676-692
17. Barnham KJ, Masters CL, Bush AI (2004) Neurodegenerative diseases and oxidatives stress. Nat Rev Drug Discov 3:205-214

18. Kong $\mathrm{Q}$, Lin CLG. Oxidative damage to RNA: mechanisms, consequences, and diseases. Cell Mol Life Sci 2010;67:1817-1829

19. Is oxidative stress related to childhood urolithiasis? Göknar N1, Oktem F, Arı E, Demir AD, Torun E. Pediatr Nephrol 2014;29(8):13816. doi: 10.1007/s00467-014-2773-z. Epub 2014 Feb 14.

20. Khan SR. Crystal-induced inflammation of the kidneys: results from human studies, animal models, and tissue culture studies. Clin Exp Nephrol 2004;8:75-88

21. Fishman AI, Green D, Lynch A, Choudhury M, Eshghi M, Konno S. Preventive effect of specific antioxidant on oxidative renal cell Injury associated with renal crystal formation. Urology 2013;82: 489.e1-7

22. Selvam R, Ravichandran V. Restoration of tissue antioxidants and prevention of renal stone deposition in vitamin $\mathrm{B} 6$ deficient rats fed with vitamin E or methionine. Indian J Exp Biol 1993;31:88288729.

23. Muthukumar A, Selvam R. Role of gluthathione on renal mitochondrial status in hyperoxaluria. Mol Cell Biochem 1998;185:77-84

24. Evaluation of oxidative stress tests in patients diagnosed with renal colic in the emergency department of Ankara Ataturk Training and Research Hospital, Turkey. Becel S, Icme F, Celik GG, Gunaydin GP, Haydar GE, Gunaydin IE, Kavakli HS, Sezgin Y. J Pak Med Assoc. 2015;65(3):242-4. 